\title{
BMJ Open Role of contextual and compositional characteristics of schools for health inequalities in childhood and adolescence: a scoping review
}

\author{
Max Herke (D) , ${ }^{1}$ Irene Moor (D) , ${ }^{1}$ Kristina Winter, ${ }^{1}$ Miriam Hack, ${ }^{1}$ \\ Stephanie Hoffmann, ${ }^{2}$ Jacob Spallek, ${ }^{2}$ Jennifer Hilger-Kolb (D) , ${ }^{3}$ Raphael Herr, ${ }^{3}$ \\ Claudia Pischke, ${ }^{4}$ Nico Dragano (D) , ${ }^{4}$ Anna Novelli (D) , ${ }^{5}$ Matthias Richter ${ }^{1}$
}

To cite: Herke M, Moor I, Winter $\mathrm{K}$, et al. Role of contextual and compositional characteristics of schools for health inequalities in childhood and adolescence: a scoping review. BMJ Open 2022;12:e052925. doi:10.1136/ bmjopen-2021-052925

- Prepublication history and additional supplemental material for this paper are available online. To view these files, please visit the journal online (http://dx.doi.org/10.1136/ bmjopen-2021-052925).

Received 03 May 2021 Accepted 29 November 2021

A Check for updates

(c) Author(s) (or their employer(s)) 2022. Re-use permitted under CC BY-NC. No commercial re-use. See rights and permissions. Published by BMJ.

For numbered affiliations see end of article.

\section{Correspondence to}

Max Herke;

max.herke@medizin.uni-halle. de

\section{ABSTRACT}

Objectives To synthesise the evidence on the role of compositional or contextual characteristics of schools in the association between students' socioeconomic position and their health in primary and secondary education in developed economies.

Design Scoping review. We included studies examining the role of at least one school or class characteristic on students' health inequalities and was published since 1 January 2000, in English or German. We searched PubMed/Medline, Web of Science and Education Resources Information Center. We provided a narrative synthesis and an overview of findings. School characteristics were grouped into five broad categories: school composition, school climate, school policies and organisation, food environment and facilities.

Results of 8520 records identified, 26 studies were included. Twelve studies found a moderating and $3 \mathrm{a}$ mediating effect. The strongest evidence came from studies examining the moderating effect of school composition, that is, the negative impact of a low individual socioeconomic position on mental health and well-being was aggravated by a low average socioeconomic position of schools. Evidence concerning the role of school climate, school stratification (eg, performance base tracking) and sponsorship, food environment and sport facilities and equipment was generally weak or very weak and mostly based on singular findings. Overall, favourable mesolevel characteristics mitigated the negative impact of low individual socioeconomic position on health outcomes. Conclusions School characteristics affect health inequalities in children and adolescents to some degree, but future research is necessary to strengthen the existing evidence and address under-represented aspects in school characteristics and health outcomes.

\section{INTRODUCTION}

\section{Rationale}

Childhood and adolescence are periods in life that are usually characterised by good health, and in which future patterns of adult health are being established. ${ }^{12}$ Encouragingly, the health status of school-aged children and

\section{Strengths and limitations of this study}

- This scoping review follows the guidelines of the 'Preferred Reporting Items for Systematic reviews and Meta-Analyses extension for Scoping Reviews'.

- This study is part of a series of scoping reviews of the German research group FOR2723, examining meso-level characteristics of the main socialising contexts of young people and their effect on health inequalities: family, kindergarten, school, vocational training, university and work as well as the impact of the healthcare system, from ages 0 to 25 .

- Childhood and adolescence are crucial life stages due to the influence of health trajectories to adulthood.

- The wide scope of the objective and the expected heterogeneity of included studies only allow for a narrative synthesis of results instead of a meta-analysis.

- This scoping review only examines children and adolescents from developed economies and focuses on students' socioeconomic position as a cause of health inequalities.

adolescents in Germany and many other European countries has improved over the last decades. ${ }^{3}$ Despite this positive development, fundamental socioeconomic differences in students' health exist. Students in socioeconomically disadvantaged families have a reasonably higher chance of becoming ill or developing early risk factors for chronic non-communicable diseases in later life. For instance, children and adolescents from families with low socioeconomic position report poorer subjective health. ${ }^{4-7}$ In addition, higher prevalence of overweight, obesity, ${ }^{3}{ }^{8}$ tobacco use ${ }^{9}$ and lower levels of physical activity have been found in this population. ${ }^{10}$ While these health inequalities are receiving renewed scientific interest, little is known about potential factors and 
mechanisms that impact the relationship between socioeconomic position and health in young people. ${ }^{11}$

Next to the family, the school represents a key institutional context for young people influencing their physical, psychological and social development. ${ }^{12}$ Students spend the majority of their weekdays at school and with a group of classmates whom they interact with. ${ }^{13}{ }^{14} \mathrm{In}$ general, the school environment can be seen as a 'multilayered phenomenon'15 that consists of classrooms, schools and school tracks. These constitute the meso level between the micro level of the individual and the macro level of states or societies, each with their own characteristics, which impact each of the other levels. Thus, classrooms represent an important educational setting for young people and differ in terms of their meso-level characteristics, such as the learning environment, student participation and the relationships between teachers, students and classmates. ${ }^{13}{ }^{16}$ In addition, particularly, primary schools are often described as comprehensive schools serving students from different socioeconomic positions and with different levels of ability, leading to a very heterogeneous composition of classrooms.

There has been a growing interest in unravelling the impact of this multilevel environment of schools on students' health and academic outcomes (eg, academic self-concept and performance), taking into account characteristics of schools and classes. ${ }^{16-18}$ Accordingly, it is important to distinguish between compositional and contextual features of schools and classes to explain differences in student outcomes not only by individuallevel but also by meso-level characteristics of the classes and schools. ${ }^{1317}$ Compositional characteristics generally refer to the (social) composition of the student body within schools and classrooms. They are often assessed by aggregating individual student information, such as sociodemographic or school-related factors (eg, perception of the learning environment or class climate) at the meso level. ${ }^{19-21}$ Contextual characteristics of schools or classes include institutional features of different school types as well as organisational, structural, cultural and physical factors of schools and classes (eg, qualification of the teaching staff, written and unwritten school norms and values, class or school size, equipment, facilities or schooling hours). Based on this literature, it is generally assumed that these characteristics are associated with cognitive and non-cognitive outcomes above and beyond students' individual cultural and social resources. ${ }^{1316-21}$

A wide range of single compositional and contextual meso-level school characteristics was investigated in previous studies. They can be broken down into five broader categories: school composition, school climate, policies, facilities and obesogenic environment.

School composition includes characteristics that result from aggregating individual-level characteristics across school classes or schools. These might include characteristics, such as the average socioeconomic position or school achievements of students, gender ratios, ethnic composition, rates of school attendance or common health behaviours of students. The impact of social comparison and reference group effects ${ }^{22}$ have been well studied in educational and psychological sciences in relation to outcomes, such as self-esteem, academic self-concept and performance, ${ }^{1522} 23$ but rarely with regard to health outcomes. ${ }^{18}$

School climate or school culture includes characteristics that describe the quality of the interactions within schools and the overall character of school life aggregated or measured at the meso level. These might relate to the teacher-student relationships, such as the way teachers control students and demand school achievements, how teachers promote autonomous learning and interactions between students, or students' perception of teaching practices, in general. Relationships between students are relevant for health and well-being as well, which pertain to the relationships between students or student's and school staff's norms regarding life in school. A positive school climate is associated with higher school satisfaction and attachment, and such a school environment, in turn, promotes a healthy physical, psychological and social development. ${ }^{182425}$

School organisation and policies include the usually codified norms and expectations present in schools, which are often enforced by staff, and which relate to aspects, such as alcohol consumption or substance use. These have been studied extensively with regards to these health behaviours and are often targeted by school interventions. ${ }^{1826-28}$

School facilities and the physical school environment, in general, can have an impact on students' health, well-being or health behaviour. The availability of, for example, a gymnasium, sports equipment on the school grounds or a swimming hall might provide opportunities for engaging in physical activity (ie, improved health behaviour), or the structural conditions of the school or its surroundings might impact students' health as well. ${ }^{18} 29$

An obesogenic environment includes all aspects of schools that reinforce unfavourable eating behaviours or low physical activity levels. This overlaps with aspects of other categories, such as policies (eg, guidelines for healthy school meals) or school facilities (eg, the availability and stocking of vending machines on school grounds). Though this might be included in other categories, it is listed separately due to the considerable attention it gained in previous research. ${ }^{30-36}$

While associations between school characteristics and overall health are well studied, little is known about possible effects of meso-level factors on the strength and direction of health inequalities prevalent among young people. This is a research gap because it can be assumed that characteristics of schools are likely to shape socioeconomic inequalities in health among children and adolescents, above and beyond individual-level characteristics. Meso-level characteristics might either mediate 
health inequalities, that is, the socioeconomic position might determine meso-level characteristics, which in turn influence health outcomes, or it might be moderated, that is, the association between socioeconomic position and health outcome change, depending on meso-level characteristics.

Several reviews already summarised studies on the direct impact of these meso-level characteristics on numerous students' health outcomes, but not their mediating or moderating role regarding health inequalities. The outcomes mostly focused on were alcohol consumption, smoking and substance use, ${ }^{186-28} 37$ eating behaviour and obesity, ${ }^{32} 33353839$ behavioural and conduct problems ${ }^{1828} 40$ or physical activity and sedentary behaviours. ${ }^{30} 31343638$

The evidence on the association between meso-level characteristics of classes or schools and students' health, well-being and health behaviours suggests that the average impact is low to moderate (eg, the impact of tobacco control policies on smoking, the association of high school attendance rates with lower rates of substance use, the relationship between a good school climate and better subjective well-being). ${ }^{18} 2627$ Some studies consider individual characteristics to mediate the effects of mesolevel characteristics ${ }^{18273134}$ or to act as a moderator. ${ }^{36}$

The examination of the wider social determinants of health ${ }^{4142}$ is necessary to extend the predominant focus on factors at the individual level as drivers of health inequalities. According to existing approaches linking more proximal macro-level determinants (eg, welfare state regimes) to health and health inequalities, ${ }^{434}$ it is conceivable that meso-level characteristics (eg, school composition, school climate, policies, facilities or obesogenic environment) may have a direct effect on health and possibly mediating or moderating the association between students' socioeconomic position and health, health behaviour and well-being. ${ }^{456}$ This expanded focus could contribute to a more comprehensive understanding of the drivers behind socioeconomic inequalities in students' health outcomes.

The aim of this scoping review was to answer the following research question: Is the association between socioeconomic position and students' health mediated or moderated by compositional or contextual characteristics of schools? This study is part of a series of scoping reviews of the German research group FOR2723, examining meso-level characteristics of the main socialising contexts of young people and their effect on health inequalities. Other reviews cover the impact of characteristics of the family, ${ }^{47}$ of kindergartens ${ }^{48}$ or of the workplace or university after leaving school ${ }^{49}$ on health inequalities.

\section{Objectives}

The objective was to retrieve and synthesise evidence about the mediating or moderating role of compositional or contextual characteristics of schools for the association between students' socioeconomic position and health.

\section{METHODS AND ANALYSIS}

The scoping review followed an extension to the original PRISMA statement 'Preferred Reporting Items for Systematic Reviews and Meta-Analyses', ${ }^{50}$ the PRISMA extension for scoping reviews (PRISMA-ScR) ${ }^{51}$ Scoping reviews are conducted to comprehensively assess the existing literature on a complex situation and/or problem. Following the PRISMA-ScR, we did not critically appraise the quality and risk of bias of the included studies or conduct a meta-analysis.

\section{Protocol and registration}

The protocol for this scoping review was published in December $2020 .^{52}$

\section{Eligibility criteria}

We included all publications in the scoping review that fulfilled the criteria regarding study design, population, determinants, outcomes, language and publication date, shown in table 1.

\section{Information sources}

We searched the following electronic databases:

- PubMed/Medline.

- Web of Science.

- Education Resources Information Center.

This selection of databases covers health, medical, educational and social sciences. We also searched the references of publications that met the inclusion criteria for further eligible sources of evidence. Grey literature was not included.

\section{Search}

We conducted the electronic searches using four blocks of search terms as well as an additional restriction by date. The summary of the electronic search strategy was as follows:

- Block 1: schools.

- Block 2: context/meso-level characteristics.

- Block 3: outcomes.

- Block 4: socioeconomic position.

- Other: date.

A full overview of all search terms for each block is given in online supplemental appendix 1. The search terms within each block were linked with the OR logical operator, and the blocks were linked with the AND operator. We searched titles and, if these were inconclusive, abstracts were screened as well. For PubMed/Medline, some of the search terms were also marked as MeSHTerms ('Medical Subject Headings'). ${ }^{39}$ The full syntax used for the electronic search in PubMed/Medline is found in online supplemental appendix 2.

\section{Selection of sources of evidence}

All search results were combined and then automatically deduplicated using a reference management software (Citavi V.6). ${ }^{53}$ Two reviewers screened titles and abstracts independently (MH and MHa). Disagreements were resolved by discussion between both reviewers. Two 
Table 1 Overview of inclusion and exclusion criteria

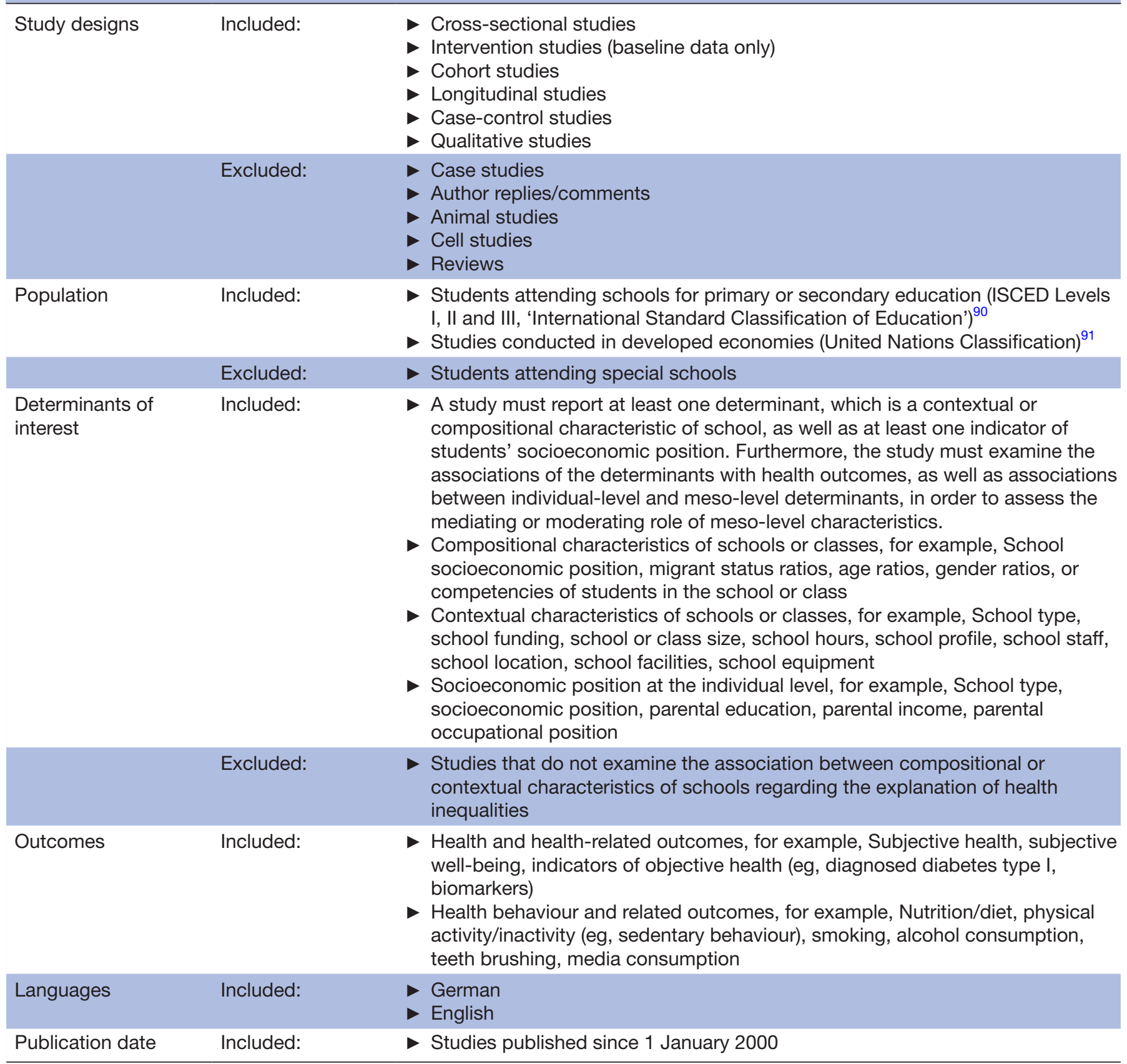

ISCED, International Standard Classification of Education.

reviewers (MHe and $\mathrm{MHa}$ ) then screened full texts of the remaining publications independently. Disagreements were discussed and resolved by a third researcher (IM), in case, no agreement could be achieved between both reviewers.

\section{Data charting process}

Two authors (MHe and MHa) independently extracted the data from all included studies using a previously developed data extraction form. One author (IM) compared and reviewed the extracted data.

\section{Data items}

The data were extracted, using a data extraction form, which was developed by one author (MHe) and tested using a convenience sample of known relevant studies from preliminary searches by three (MHe, MHa and IM). Extracted information included the following data:

- Author names.

- Year of publication.

- Year that study was conducted.

- Country of sample origin.

- Study design. 
- Number of participants.

- Sociodemographic characteristics of participants

- Socioeconomic position of participants.

- Compositional and contextual characteristics of schools.

- Outcome measures.

- Analytic strategy.

- Short summary of main findings.

\section{Critical appraisal of individual sources of evidence}

Since a critical appraisal is not foreseen when conducting scoping reviews, ${ }^{51}$ we did not provide a critical appraisal of individual sources of evidence.

\section{Synthesis of results}

Due to the wide scope of the review and the heterogeneity in methods, outcomes and determinants in the included publications, we conducted a narrative synthesis of findings following the guidance of the Centre for Reviews and Dissemination. ${ }^{54}$ For the narrative synthesis, we first examined whether mesolevel characteristics of the included studies could be matched to the broad categorisations (ie, school composition, school climate, school organisation and policies, obesogenic environment and school facilities) we had previously developed based on our preliminary research. As expected, the included studies were very heterogeneous in terms of the meso-level characteristics included, which were examined as mediators or moderators of health inequalities. These characteristics were ultimately used to explore relationships within and across studies and to compare findings across studies. We discussed whether grouping the included studies according to the existing category system would be useful, which categories to assign them to, and whether additional categories might need to be introduced or existing ones modified. Regarding population (students in developed economies), outcomes (different aspects of health) or other determinants (socioeconomic position), the studies were quite homogeneous by inclusion criteria, and groupings by other characteristics (eg, the country in which the study was conducted, a distinction between longitudinal and cross-sectional designs, analysis strategies) were also discussed but rejected. When presenting the individual results of each study, the results were first summarised according to these groupings. In the subsequent synthesis, a broader overview of the results was developed, including the populations considered, the analytic strategies used and the underlying theoretical frameworks that the publications were based on. The narrative synthesis was supplemented by further approaches to summarise the studies and visualise their key findings, that is, a tabulated summary provided an overview of the studies' characteristics and harvest plots helped visualise the results. ${ }^{55}$

\section{Patient and public involvement}

This research was done without patient involvement. Patients were not invited to comment on the study design and not consulted to develop patient-relevant outcomes or interpret the results. Patients were not invited to contribute to the writing or editing of this document for readability or accuracy.

\section{RESULTS}

\section{Selection of sources of evidence}

The electronic search from 18 November 2020 yielded a total of 8322 sources after deduplication. After the first screening, we discarded 8098 sources. We obtained full texts for 224 sources for further assessment. A total of 198 sources did not meet the inclusion criteria and were discarded. Most of these sources either did not include any or suitable measures of socioeconomic position (eg, neighbourhood or migration background as proxies for socioeconomic position) in their analyses or did not test for the moderation or mediation of health inequalities. Fewer sources were excluded because they were missing relevant health outcomes (eg, aggregated health outcomes), were intervention studies that did not include relevant data at baseline, did not include relevant mesolevel characteristics in their analyses (eg, focused on kindergartens) or because of other reasons (eg, used data from economies in transition or developing economies, were only study protocols, were in different languages). We included 26 research papers in the scoping review. The selection process is presented in figure 1 .

\section{Characteristics of sources of evidence}

Twenty-six studies met the inclusion criteria. ${ }^{45} 56-81$ Two studies analysed international data from either 33 developed countries or six European countries, respectively. ${ }^{458}$ Ten studies covered the USA, ${ }^{58616265707173757781}$ five the UK, ${ }^{5759727680}$ two the Netherlands, ${ }^{5666}{ }^{67}$ two Finland, ${ }^{7879}$ and one each Australia, ${ }^{69}$ France, ${ }^{60}$ Germany, ${ }^{63}$ Norway ${ }^{64}$ and Sweden. ${ }^{74}$ The sample sizes differed widely, ranging from 184160 in the largest international study, and approximately 184000 students in the largest national study, down to 108 in the smallest quantitative one, and 36 in the single included qualitative study. Four studies implemented a longitudinal design $^{57586177}$ and 22 were cross-sectional. ${ }^{45} 596062-76$ 78-81 Only one of the studies analysed data from a qualitative survey ${ }^{80}$ all others analysed quantitative data. An overview of the study characteristics is given in table 2. Further characteristics which were summarised include the year the data were collected, more detailed information on the location of the study, where available, the age and grade levels of the included students as well as the number of schools examined in each study.

\section{Results of individual sources of evidence}

School composition

Four studies (Goodman et al, ${ }^{62}$ Martin et al, ${ }^{71}$ Moore et $a l^{72}$ and Shackleton $e t a l^{76}$ ) examined the average 


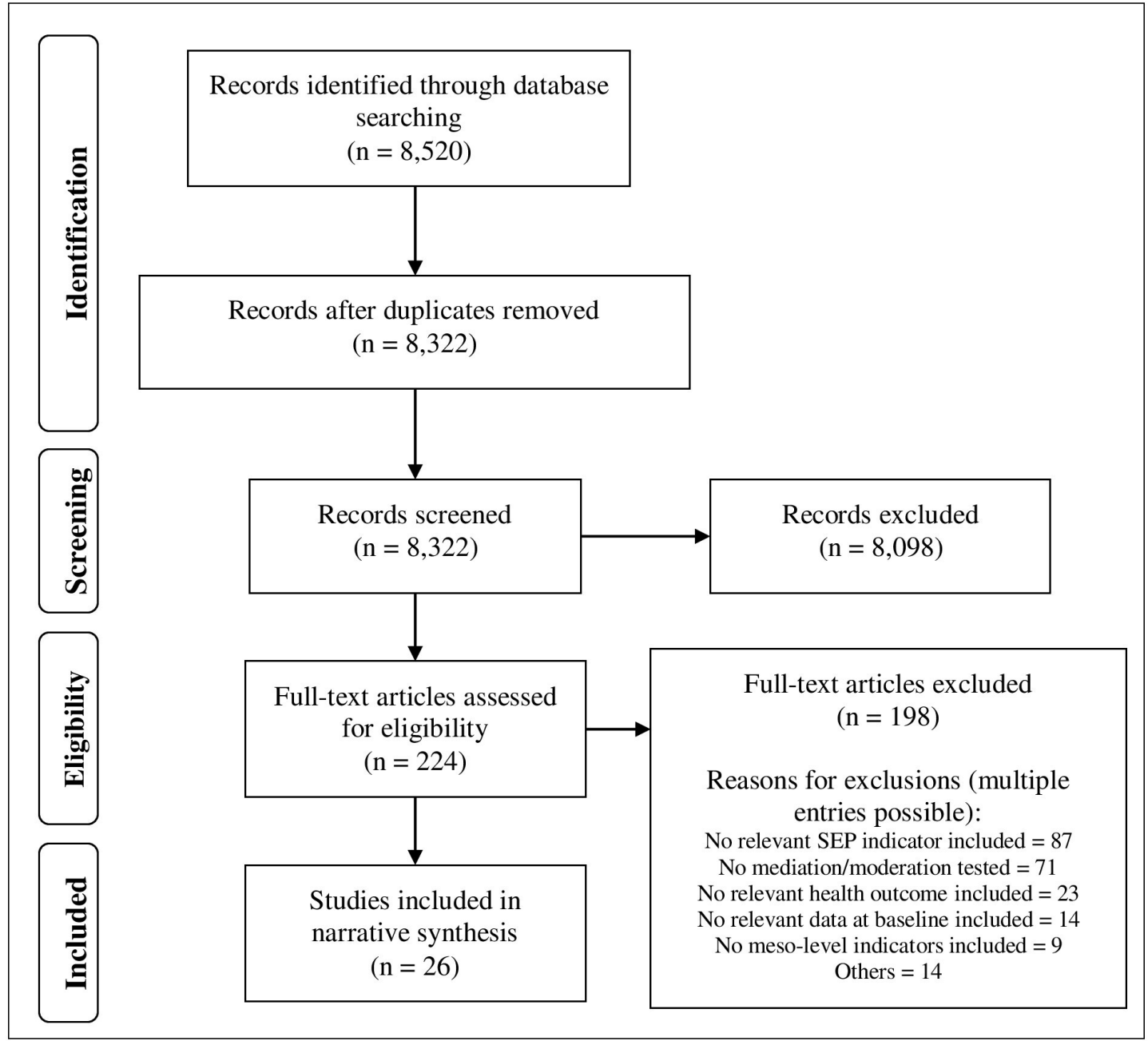

Figure 1 PRISMA flow diagram. PRISMA, Preferred Reporting Items for Systematic Reviews and Meta-Analysis; SEP, socioeconomic position.

socioeconomic position of schools as a moderator of health inequalities for adolescents. In all four, a low socioeconomic position of the school aggravated the negative impact of a low individual socioeconomic position on students' health outcomes, that is, depressive symptoms, BMI (Body Mass Index), life satisfaction and risky health behaviours, well-being and quality of life. Furthermore, Shackleton $e t a l^{76}$ reported a negative impact of a higher discordance between individual and school-level socioeconomic position on antisocial behaviour. However, Moore $e t a l^{72}$ also tested six other outcomes (ie, physical activity, eating habits, smoking, alcohol consumption, substance use, self-rated health and life satisfaction) and found no moderation.

Three studies (Huisman and Bruggeman ${ }^{66}$ Olsson and Fritzell $^{74}$ and Lewis et al) ${ }^{69}$ examined characteristics of school composition as mediators for health inequalities. Huisman and Bruggeman ${ }^{66}$ found that a high percentage of smokers among friends mediated the negative impact of a low school type (ie, schools that did not provide academic preparatory education) on adolescents' smoking, though in this case, school type was used as a proxy for students' socioeconomic position. Olsson and
Fritzell $^{74}$ and Lewis $e t a l^{69}$ also examined schools' average socioeconomic position and Olsson and Fritzell ${ }^{74}$ also the proportion of students with migration background but found no mediation of inequalities in health behaviour.

\section{School climate}

Five studies (Bonell et al, ${ }^{57}$ Grüttner, ${ }^{63}$ Piccolo et $a l,{ }^{75}$ Virtanen et $a l^{78}$ and Youngblade $\left.e t a l^{81}\right)$ examined a wide variety of meso-level characteristics with regards to school climate (eg, engaging school environment, student commitment, psychosocial climate among teachers, school violence) and their role for health inequalities of students in secondary education. Bonell $e t a p^{7}$ reported that a positive student commitment in school mitigated the negative impact of low family affluence on smoking, though only for non-white students and not for other school climate indicators (ie, engaging school environment, staff relationships with students, integration of students' academic education and broader social development or school-community relationships) and other outcomes (ie, alcohol consumption and substance use). Piccolo $e t a l^{75}$ found that better support in school mitigated the negative impact of low family income on 


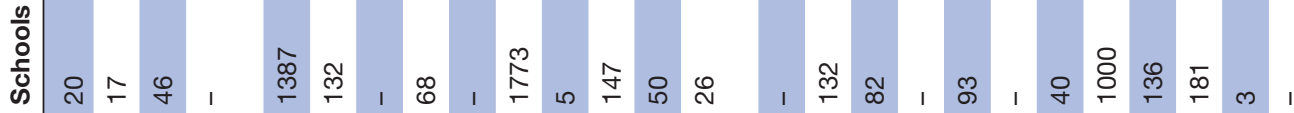

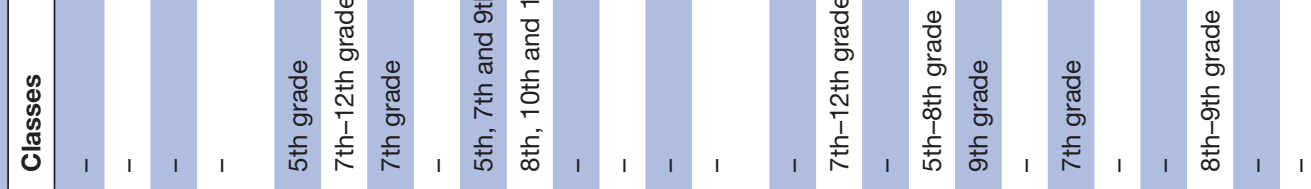

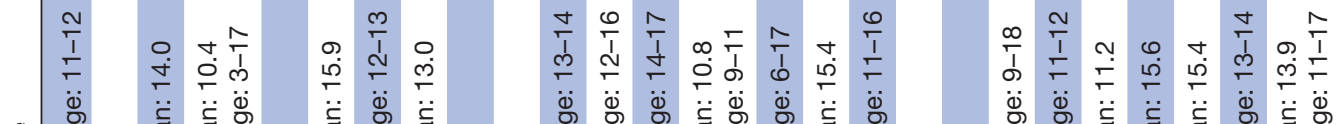

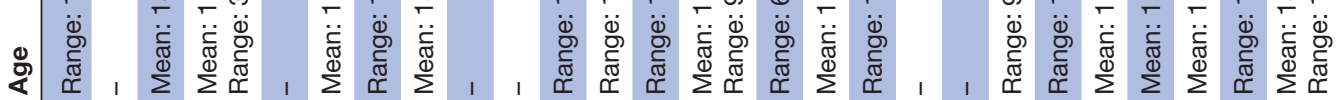

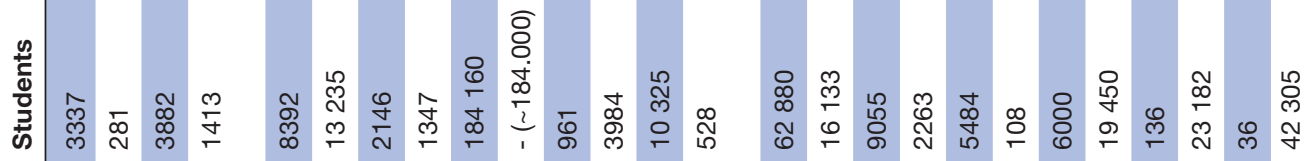

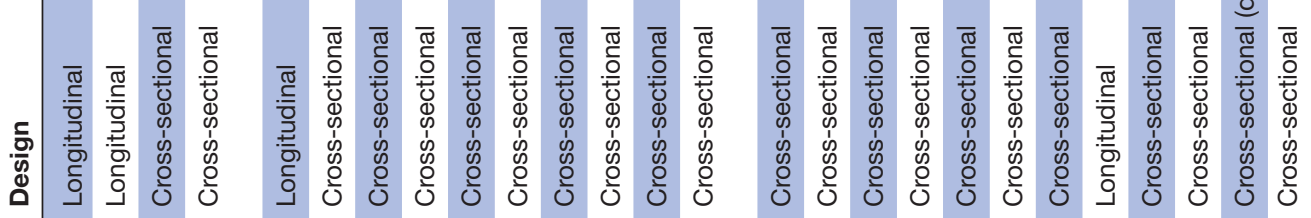

을 홍

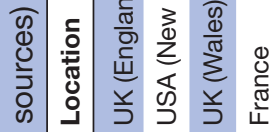
$\stackrel{\circ}{\mathrm{N}}$

蒿 ब

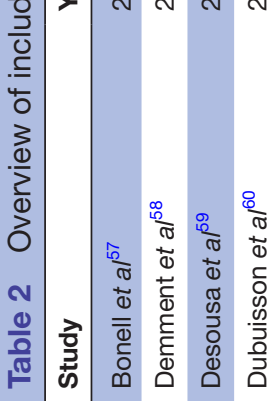

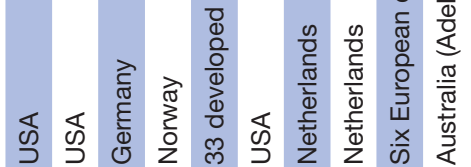

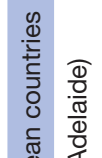

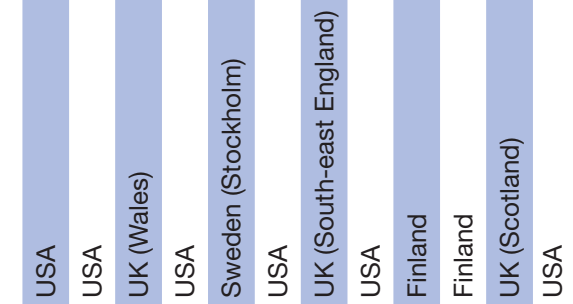

ठั

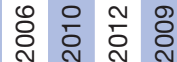

ำ

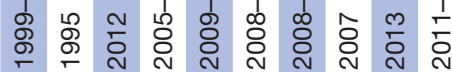

$\stackrel{8}{\frac{8}{5}}$

$\stackrel{\bar{\sigma}}{\mathrm{E}}$

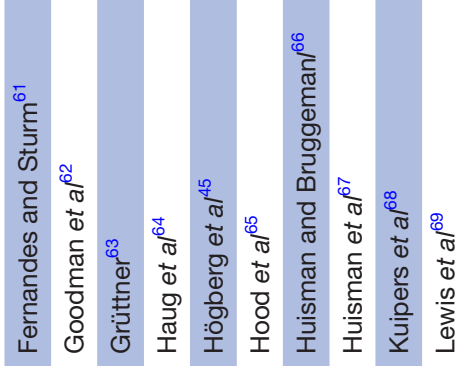

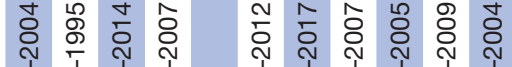

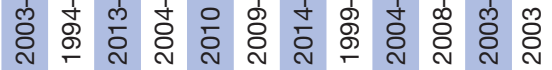

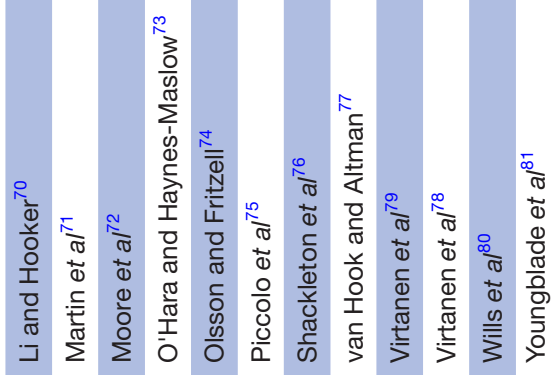


students' cortical thickness, though not for executive function (measured via tasks from the National Institute of Health Toolbox Cognition Battery) ${ }^{82}$ The other studies found no impact of school climate indicators on health inequalities as either mediators or moderators.

\section{School organisation and policies}

Six studies (Desousa et al,$^{59}$ Högberg et $a l,{ }^{45}$ Huisman et $a l,{ }^{67}$ Kuipers et $a l,{ }^{68}$ Lewis $e t a l^{69}$ and Li and Hooker) ${ }^{70}$ examined some aspects of policy or organisation with regards to schools and their impact on health inequalities among adolescents or in case of $\mathrm{Li}$ and Hooker ${ }^{70}$ also for children from 6 years. Högberg $e t a t^{45}$ conducted an international comparison and reported that higher school stratification (measured via a modified version of the index of between-school horizontal stratification by the OECD (Organisation for Economic Co-operation and Development) ${ }^{83}$ mitigated the negative impact of low family affluence on students psychological and psychosomatic health complaints. Li and Hooker ${ }^{70}$ reported that public sponsorship of schools-in contrast to private sponsorship-aggravated the negative impact of household poverty on BMI. Finally, Huisman et $a{ }^{67}$ found that a low school type (ie, schools that did not provide academic preparatory education) mediated the negative impact of lower parental education on adolescents' smoking. Neither Desousa et $a \tilde{l}^{p 9}$ examining school alcohol policies nor Kuipers et $a l^{68}$ examining several indicators regarding school smoking policies found any moderation for health inequalities in alcohol consumption or smoking, respectively. Lewis et al found no mediation of inequalities in physical behaviour by school policies.

\section{Obesogenic environment}

Three studies (O'Hara and Haynes-Maslow, ${ }^{73}$ Virtanen et $a l^{78}$ and van Hook and Altman) ${ }^{77}$ examined the moderating impact of fast food availability in schools through several indicators (ie, vending machines on school premises, distance to fast food restaurants from school, competitive food sales) on adolescents' health inequalities. However, only Virtanen $e t a l^{78}$ found that higher fast food availability aggravated the negative impact of parental education on eating habits. O'Hara found no impact regarding inequalities in eating habits, physical activity, sedentary behaviour or BMI and van Hook and Altman ${ }^{77}$ found not effect inequalities in the change of BMI from fifth to eighth grade.

Three studies (Demment et $a l^{58}$ Wills et $a l^{80}$ and Dubuisson et $a l)^{60}$ examined other aspects of the obesogenic environment. Demment et a $\vec{p}^{8}$ found that a better nutrition and physical activity environment of schools' increased the positive impact of high household income on BMI, though not the negative impact of low household income. Wills et $a l^{80}$ - the only qualitative study included in this review-reported that better eating habits of peers might mitigate the negative impact of low family socioeconomic position on adolescents eating habits. Finally, Dubuisson et a $b^{60}$ examined the impact of school canteen attendance on inequalities in eating habits and sedentary behaviour in children as well as adolescents but found no moderation.

\section{School facilities}

Four studies (Fernandes and Sturm, ${ }^{61}$ Lewis et al, ${ }^{69}$ Haug et $a l^{64}$ and Hood et $a l^{65}$ examined the impact of the availability and/or quality of sports facilities and equipment on school premises on adolescent health inequalities regarding physical activity or BMI. Fernandes and Sturm ${ }^{61}$ reported better sports facilities to mediate the association between household income and physical activity, though not for BMI. Also, Hood et $a l^{65}$ reported that they moderated this association with BMI, that is, mitigating the negative impact of low parental education on BMI. However, Lewis $e t a l^{69}$ found no mediation and Haug et $a b^{64}$ found no moderation regarding physical activity.

\section{Synthesis of results}

The findings were mostly mixed, as of the 26 included studies, only 12 studies found a moderating and three a mediating effect of meso-level characteristics on students' health inequalities. The evidence for the moderation of health inequalities by the average socioeconomic position of the school is the strongest, as these findings were replicated over several studies. Four studies reported that a low average socioeconomic position of the school aggravated the negative impact of a low individual socioeconomic position on adolescents's health. Almost all other evidence is based on singular findings without directly comparable studies, with the exception of fast food availability, which was found to have almost no moderating impact on health inequalities. A full overview is presented in table 3.

The focus of the studies was clearly on the moderating effects of meso-level characteristics on student health inequalities. On the one hand, unfavourable meso-level characteristics were shown to reinforce health inequalities, for example, the low average socioeconomic position of students within a school or high fast food availability put a double burden on students with low individual socioeconomic position. On the other hand, favourable meso-level characteristics have the potential to decrease health inequalities, for example, better sports facilities and equipment or better academic support in school can improve health equity. Thus, changes and interventions at the level of school contexts have the potential to have at least a slight impact on health inequalities and to reduce them.

In case of mediations, students' lower socioeconomic position was associated with unfavourable meso-level characteristics, which in turn were associated with worse health outcomes (eg, through a higher percentage of smokers among friends, or through worse availability of sports facilities and equipment).

Regarding population, the included studies almost exclusively focused on students in secondary education. Only Dubuisson et $a b^{60}$ and $\mathrm{Li}$ and Hooker ${ }^{70}$ included 


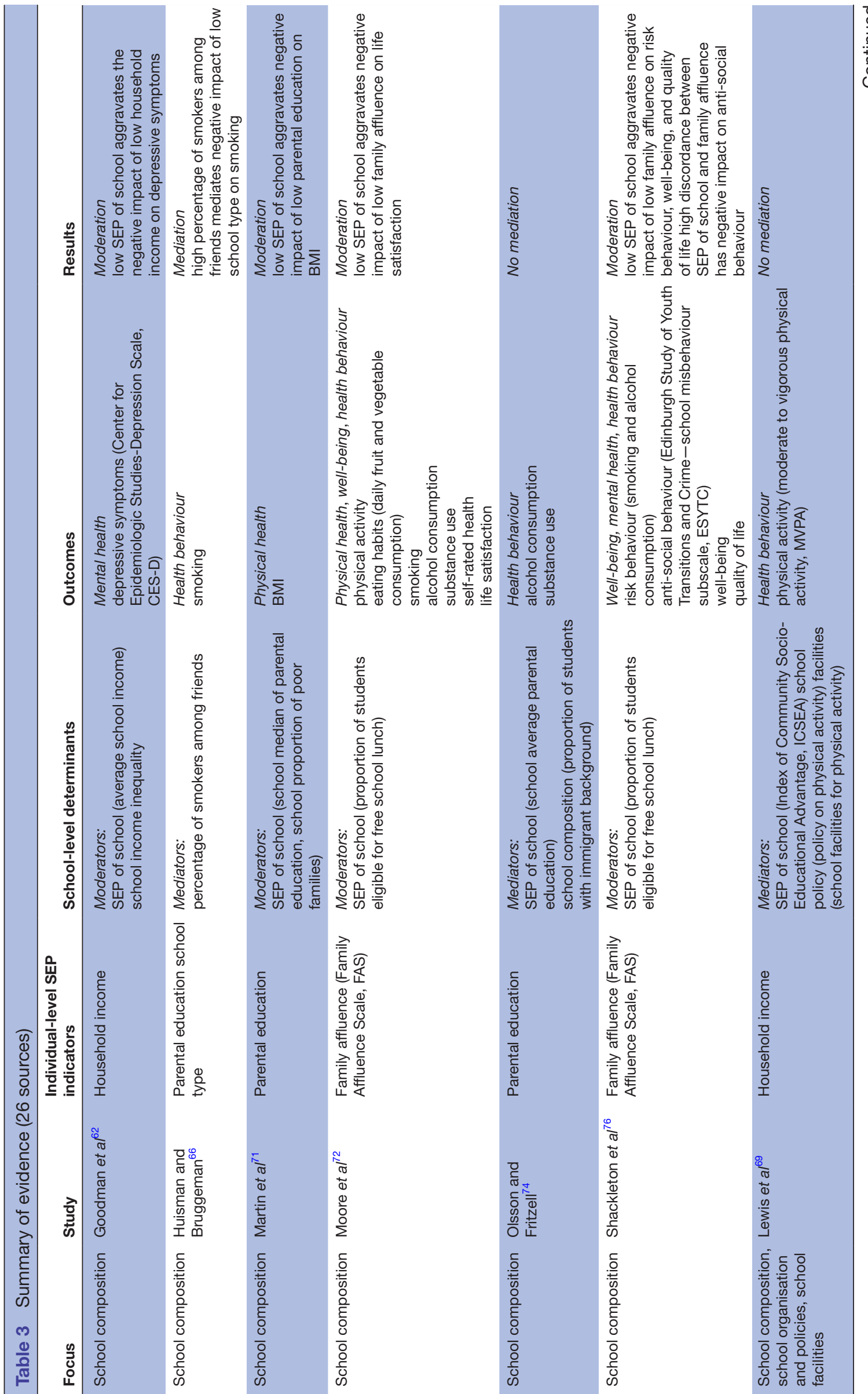




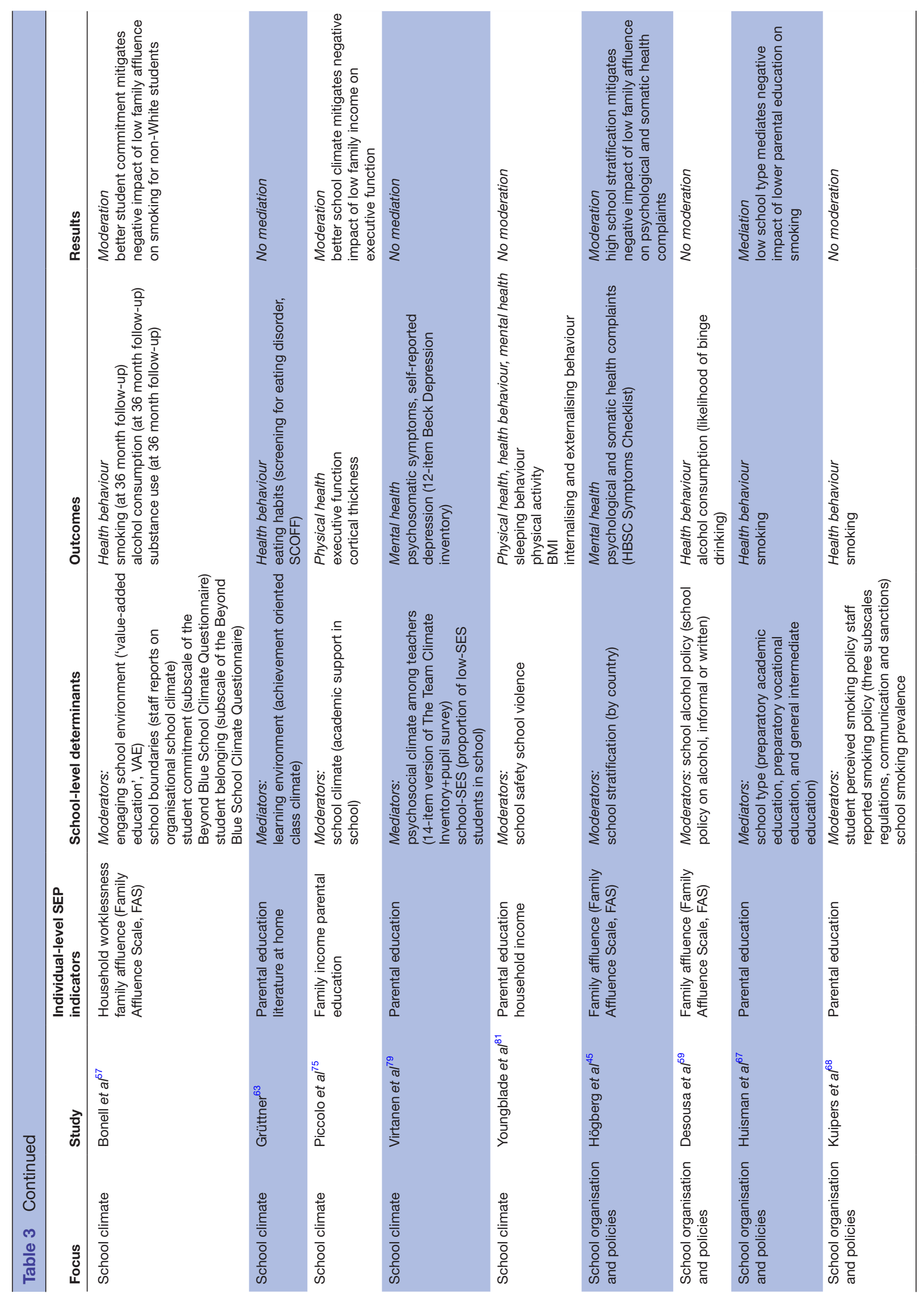




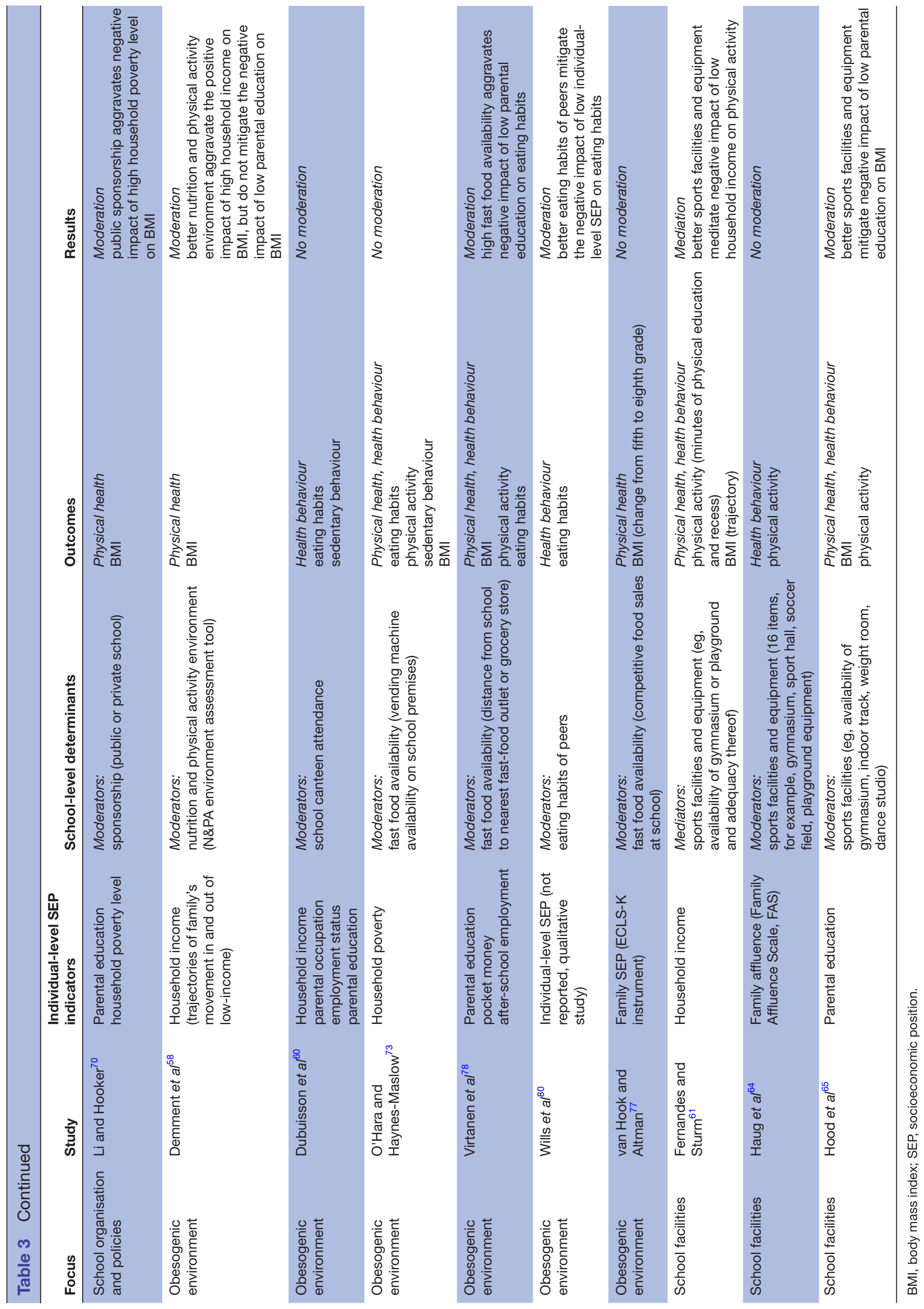

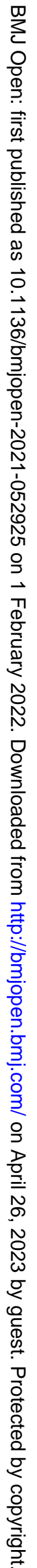




\begin{tabular}{|c|c|c|c|}
\hline School characteristic & Physical health & $\begin{array}{l}\text { Mental health and well- } \\
\text { being }\end{array}$ & Health behaviour \\
\hline School composition & & & \\
\hline School climate & & & \\
\hline Policies and organisation & & & \\
\hline Food environment & & & \\
\hline Facilities & & & \\
\hline
\end{tabular}

Figure 2 Harvest plot of findings for each analysed outcome, grouped by school characteristics and health outcomes. Notes: The height of the bars corresponds to the study's sample sizes on a logarithmic scale. =Mediation. *=Moderation. Black bar=mediation or moderation found. Grey bar=no mediation or moderation found.

children in primary education, and only the latter found a moderating effect of school organisation in the form of public or private sponsorship. The analytical strategies were mostly deemed adequate. Fourteen studies, including all studies examining school composition, employed some sort of mixed models, using random effects to account for the nesting of students within schools and in case of analyses of moderations, the inclusion of some cross-level interaction terms. Eleven studies relied on other regression models without random effects, using interactions or split samples to examine moderations, or nested models to examine mediations. One study employed an exploratory qualitative design, interviewing students using semistructured interviews.

An overview of the findings of each analysed outcome is presented as a harvest plot in figure 2. For this overview, the results were further grouped by outcomes and it shows that the majority of analyses did not provide evidence for a mediation or moderation of students' health inequalities by school characteristics.

\section{DISCUSSION}

\section{Summary of evidence}

This scoping review included 26 studies, involving students from developed economies. The studies examined a wide variety of school characteristics as mediators or moderators of health inequalities. All school characteristics could be incorporated in our preliminary framework, which distinguished five broad categories: school composition, school climate, school policies and organisation, food environment and facilities.

Studies examining school composition and more specifically the moderating effect of the average socioeconomic position of the school on adolescents' health inequalities were among the most rigorous regarding the analytical strategy, describing the methodology thoroughly, employing mixed models and testing cross-level interactions. They showed evidence for a small effect, that is, the negative impact of a low individual socioeconomic position being aggravated by a low average socioeconomic position of schools, mostly with regards to mental health and well-being. However, the transferability of results is limited because of the validity of some indicators used, depending on the country and school system examined (eg, the percentage of students eligible for free school lunch). This aspect of schools was covered by the great majority of the studies, but many other compositional characteristics were ignored altogether (eg, students' competencies or gender ratios).

Regarding all other categories, the included studies mostly provided weak or very weak evidence for a moderation or mediation of adolescents' health inequalities, as most findings were based on singular studies or could not be replicated over several studies (eg, findings regarding fast food availability in schools moderating inequalities in eating habits). For school climate, findings provided very weak evidence for a moderation of health inequalities, that is, a better school climate mitigating the negative impact of a low individual socioeconomic position 
on health. However, these findings are strongly limited by the great heterogeneity of the used school climate measures as well as analytical strategies. For school policies and organisation, the findings showed an impact of some organisational features such as school stratification or sponsorship on health inequalities but not for healthrelated school policies. Higher school stratification and decreased and public sponsorship increased health inequalities, whereas school types mediated them. For food environment, the impact of higher availability of fast food was examined in four studies, but only one found it aggravating the negative impact of a low individual socioeconomic position for a singular outcome, eating habits. One study reported a reinforcement of the impact of a high individual socioeconomic position on BMI by a school environment, that supported healthy nutrition and physical activity, and the singular qualitative study reported positive eating habits of peers mitigating negative effects of a low individual socioeconomic position on adolescents' own eating habits. Finally, for facilities, the included studies exclusively examined the availability and quality of sports facilities, which were shown to mediate health inequalities in one study and to moderate it in another, that is, better availability mitigating the negative impact of a low individual socioeconomic position on BMI.

Most studies did not have a deeper theoretical underpinning and considered individual and meso-level characteristics solely as risk or protective factors. Only a few studies further explicated a theoretical model. For example, the theory of human functioning and school organisation, ${ }^{84}$ reference group effects and the big-fishlittle-pond effect, ${ }^{85}$ or social network theories. ${ }^{86}$ Adolescents spend an extremely large amount of time in school, and much of this in the classroom with peers who have the same developmental tasks to accomplish. The importance of contexts and social networks for human development has long been the subject of research, ${ }^{87}$ but in the context of adolescent health research, it is only comparatively recently that research has gone beyond the importance of individual characteristics, increasingly including characteristics at the level of schools. School environment plays an essential role in shaping students' health and well-being. Mismatches between the social resources of the learning environment in classes and schools and students' developmental needs and abilities can negatively impact their overall life satisfaction or psychosomatic health, as the resources of the learning environment are instrumental in mastering developmental tasks. ${ }^{138}$ The relevance of the school context also results from the class as an interaction partner. The other adolescents, by virtue of the time spent together alone, are a central reference group with which adolescents compare themselves, for example, by placing the individual in relation to the contextual and compositional characteristics of the school class. From these comparisons, that is, from the interactions of individual characteristics with those of the school environment, their own effects on health and well-being can emerge. School classrooms are places where adolescents must confront such reference group comparisons both in terms of their academic performance and in all other aspects of their physical, cognitive, emotional and social development. ${ }^{1389}$

\section{Strengths and limitations}

This scoping review is part of a series of other reviews by the German research group FOR 2723, whose various subprojects examine the most important contexts of young people and their significance for health or health inequalities, covering family, ${ }^{47}$ kindergarten, ${ }^{48}$ school and following contexts such as university or vocational training. ${ }^{49}$ Together, these works form an overview of even greater scope than this review alone. Further benefits arise from the scoping review method itself. It is a tool for mapping broad subject areas. First, it could be used to identify clusters of research findings that represent trends in current research and could possibly be addressed in more focused reviews (eg, the studies on the influence of average socioeconomic position, which could possibly even be combined in a meta-analysis). On the other hand, unusual results or rare designs could also be considered (eg, the single qualitative study, or the study on the influence of school climate on cortical thickness or executive function). Furthermore, the methodology according to the guideline of the PRISMA-ScR ${ }^{51}$ is relatively strict and follows a transparent and rigorous process (eg, each search results and each study were screened by at least two authors for possible inclusion).

However, this work is also subjected to several limitations. This review is mostly exploratory in nature and provides an overview of current research but cannot provide in-depth analyses to answer more specific research questions. Therefore, several sources of bias for this scoping review must be emphasised. As there was no meta-analysis conducted, this review did not report effect sizes and only shortly summarised the main findings, providing only an overview of the field, not an assessment of the magnitude of the examined effects. Therefore, the used analytical strategies as well as the sample sizes of the included studies were not regarded in depth, and average effect sizes for the mediating or moderating role of school characteristics could not be determined, and the assessment of the quality of evidence is limited without a critical appraisal of the included studies. There was a distinct lack of comparability for most of the studies, and, therefore, most results of this review are based on singular findings. In addition to the differences between the meso-level characteristics studied and the indicators used, there are also differences by country that can affect the results. Furthermore, we did not examine children and adolescents from less developed economies or factors other than socioeconomic position as a cause of health inequalities. Finally, formal limitations made for enhancing the manageability of this scoping review might have introduced further bias, that is, the restriction to studies in English or German and to publications from 
the year 2000 onwards as well as the exclusion of certain groups, such as children in special schools.

\section{CONCLUSIONS}

The objective was to retrieve and synthesise evidence about the mediating or moderating role of compositional or contextual characteristics of schools for the association between socioeconomic position and health children and adolescents attending primary or secondary education. We were able to identify a wide range of studies that addressed this issue, including several clusters of research activity, and summarise and synthesise results from some studies with moderate evidence, but for the most part only single studies with low evidence. A key finding was confirmed across multiple studies, namely, that the negative effects of a low socioeconomic position were exacerbated by a low average socioeconomic position of schools, especially in relation to students' mental health and well-being. In addition, other important findings on moderation effects were also found, either in the form that favourable meso-level characteristics (eg, good school climate, private sponsorship) moderated student health inequalities or that unfavourable meso-level characteristics (eg, easier availability of fast food) increased health inequalities. In general, few studies examined the mediating effect of meso-level characteristics on health inequalities, that is, that the impact of students' socioeconomic position on health was mediated by mesolevel characteristics (ie, extent of performance-based school tracking, physical education facility equipment, percentage of smokers among friends in school). In sum, the findings from the scoping review underline that some meso-level school characteristics are associated with health inequalities in children and adolescents.

Further studies examining the mediating or moderating effects of school characteristics for health inequalities in children and adolescents are warranted to strengthen the existing evidence and address underrepresented aspects in school characteristics and health outcomes. Except for the role of one central characteristic of school composition (ie, the average socioeconomic position of the schools' students) as well as few aspects of school climate (eg, learning environment), food environment (eg, fast food availability) or facilities (ie, availability of sports facilities and equipment), only a small section of the research field has been covered so far. However, future studies need to address or avoid several limitations present in the current research. Regarding school characteristics, future studies need to extend their focus (eg, using other indicators than socioeconomic position such as gender ratio when examining school composition, or other facilities such as libraries when examining school facilities) or narrow their focus (eg, using more validated indicators for examining school climate). Regarding health outcomes, future studies need to put more emphasis on indicators of physical health as well as mental health and well-being indicators.
Author affiliations

${ }^{1}$ Institute of Medical Sociology, Medical Faculty, Martin-Luther-University HalleWittenberg, Halle (Saale), Germany

${ }^{2}$ Department of Public Health, Brandenburg University of Technology, Senftenberg, Germany

${ }^{3}$ Mannheim Institute of Public Health, Social and Preventive Medicine, Heidelberg University, Mannheim, Germany

${ }^{4}$ Institute of Medical Sociology, Centre for Health and Society, Medical Faculty, Heinrich Heine University Düsseldorf, Düsseldorf, Germany

${ }^{5}$ Chair of Health Economics, Technical University of Munich, München, Germany

Twitter Matthias Richter @mrich_er

Contributors MH drafted the manuscript. MH, JH-K, IM and MR contributed to the development of the selection criteria. $\mathrm{MH}$ conducted the searches. $\mathrm{MH}, \mathrm{MHa}$ and IM selected the studies and extracted the data. MH, IM, KW, SH, JS, JH-K, RH, $\mathrm{CP}, \mathrm{ND}, \mathrm{AN}$ and MR critically revised the draft manuscript for important intellectual content. All authors read and approved the final version of the manuscript. MR is the guarantor for this work.

Funding This work was supported by the German Research Foundation (DFG) grant number FOR2723 (project number 384210238). The individual grant numbers for this sub-project and the coordination project are RI2467/8-1 and RI2467/9-1.

Competing interests None declared.

Patient consent for publication Not applicable.

Ethics approval This study does not involve human participants.

Provenance and peer review Not commissioned; externally peer reviewed.

Data availability statement Data sharing not applicable as no datasets generated and/or analysed for this study. No additional data available.

Supplemental material This content has been supplied by the author(s). It has not been vetted by BMJ Publishing Group Limited (BMJ) and may not have been peer-reviewed. Any opinions or recommendations discussed are solely those of the author(s) and are not endorsed by BMJ. BMJ disclaims all liability and responsibility arising from any reliance placed on the content. Where the content includes any translated material, BMJ does not warrant the accuracy and reliability of the translations (including but not limited to local regulations, clinical guidelines, terminology, drug names and drug dosages), and is not responsible for any error and/or omissions arising from translation and adaptation or otherwise.

Open access This is an open access article distributed in accordance with the Creative Commons Attribution Non Commercial (CC BY-NC 4.0) license, which permits others to distribute, remix, adapt, build upon this work non-commercially, and license their derivative works on different terms, provided the original work is properly cited, appropriate credit is given, any changes made indicated, and the use is non-commercial. See: http://creativecommons.org/licenses/by-nc/4.0/.

\section{ORCID iDs}

Max Herke http://orcid.org/0000-0001-6425-4366 Irene Moor http://orcid.org/0000-0003-3245-5176

Jennifer Hilger-Kolb http://orcid.org/0000-0003-0347-1900

Nico Dragano http://orcid.org/0000-0002-0378-0757

Anna Novelli http://orcid.org/0000-0002-4600-0183

\section{REFERENCES}

1 Green MJ, Stritzel H, Smith C, et al. Timing of poverty in childhood and adolescent health: evidence from the US and UK. Soc Sci Med 2018;197:136-43.

2 Sawyer SM, Afifi RA, Bearinger LH, et al. Adolescence: a foundation for future health. Lancet 2012;379:1630-40.

3 Inchley J, Currie D, Jewell J. Adolescent obesity and related behaviours: trends and inequalities in the who European region 20022014: observations from the health behaviour in school-aged children (HBSC) who Collaborative cross-national study. Copenhagen: WHO Regional Office for Europe, 2017.

4 Magklara K, Skapinakis P, Niakas D, et al. Socioeconomic inequalities in general and psychological health among adolescents: a cross-sectional study in senior high schools in Greece. Int J Equity Health 2010;9:3.

5 Heilmann K, Bräsen J, Herke M. Soziale Determinanten Der subjektiven Gesundheit, Lebenszufriedenheit und krankheitsbedingten Schulfehltage von Heranwachsenden in 
Deutschland: Erste Ergebnisse des Nationalen Bildungspanels (NEPS). Gesundheitswesen 2018;80:613-20.

6 Duinhof EL, Stevens GWJM, van Dorsselaer S, et al. Ten-Year trends in adolescents' self-reported emotional and behavioral problems in the Netherlands. Eur Child Adolesc Psychiatry 2015;24:1119-28.

7 Reiss F. Socioeconomic inequalities and mental health problems in children and adolescents: a systematic review. Soc Sci Med 2013:90:24-31.

8 Knai C, Lobstein T, Darmon N, et al. Socioeconomic patterning of childhood overweight status in Europe. Int J Environ Res Public Health 2012:9:1472-89.

9 Hublet A, Bendtsen P, de Looze ME, et al. Trends in the cooccurrence of tobacco and cannabis use in 15-year-olds from 2002 to 2010 in 28 countries of Europe and North America. Eur J Public Health 2015;25 Suppl 2:73-5.

10 Kalman M, Inchley J, Sigmundova D, et al. Secular trends in moderate-to-vigorous physical activity in 32 countries from 2002 to 2010: a cross-national perspective. Eur J Public Health 2015;25 Suppl 2:37-40.

11 Richter M, Moor I, van Lenthe FJ. Explaining socioeconomic differences in adolescent self-rated health: the contribution of material, psychosocial and behavioural factors. J Epidemiol Community Health 2012:66:691-7.

12 Bilz L, Sudeck G, Bucksch J. Schule und Gesundheit: Ergebnisse des WHO-Jugendgesundheitssurveys "Health Behaviour in Schoolaged Children". Weinheim, Basel: Beltz Juventa, 2016.

13 Eccles JS, Roeser RW. Schools as developmental contexts during adolescence. J Res Adolesc 2011;21:225-41.

14 Bildungssystem RK. Wohlfahrtsstaat und gesundheitliche Ungleichheit. ein internationaler Vergleich für das Jugendalter. Wiesbaden: VS Verlag für Sozialwissenschaften, 2015.

15 Rumberger RW, Palardy GJ. Does segregation still matter? the impact of student composition on academic achievement in high school. Teachers College Record 2005;107:1999-2045.

16 Allodi MW. The meaning of social climate of learning environments: some reasons why we do not care enough about it. Learn Environ Res 2010;13:89-104.

17 Kidger J, Araya R, Donovan J, et al. The effect of the school environment on the emotional health of adolescents: a systematic review. Pediatrics 2012;129:925-49.

18 Sellström E, Bremberg S. Is there a "school effect" on pupil outcomes? A review of multilevel studies. $J$ Epidemiol Community Health 2006;60:149-55.

19 Bonell C, Jamal F, Harden A, et al. Systematic review of the effects of schools and school environment interventions on health: evidence mapping and synthesis. Public Health Res 2013;1:1-320.

20 Modin B, Östberg V. School climate and psychosomatic health: a multilevel analysis. Sch Eff Sch Improv 2009;20:433-55.

21 Andersson HW, Bjørngaard JH, Kaspersen SL, et al. The effects of individual factors and school environment on mental health and prejudiced attitudes among Norwegian adolescents. Soc Psychiatry Psychiatr Epidemiol 2010;45:569-77.

22 Van de gaer E, Grisay A, Schulz W. The reference group effect: an explanation of the paradoxical relationship between academic achievement and Self-Confidence across countries. J Cross Cult Psychol 2012;43:1205-28.

23 Fang J, Huang $X$, Zhang M, et al. The Big-Fish-Little-Pond effect on academic Self-Concept: a meta-analysis. Front Psychol 2018;9:1-11.

24 Aldridge JM, McChesney K. The relationships between school climate and adolescent mental health and wellbeing: a systematic literature review. Int J Educ Res 2018;88:121-45.

25 Kutsyuruba B, Klinger DA, Hussain A. Relationships among school climate, school safety, and student achievement and well-being: a review of the literature. Rev Educ 2015;3:103-35.

26 Aveyard P, Markham WA, Cheng KK. A methodological and substantive review of the evidence that schools cause pupils to smoke. Soc Sci Med 2004;58:2253-65.

27 Bonell C, Parry W, Wells $\mathrm{H}$, et al. The effects of the school environment on student health: a systematic review of multi-level studies. Health Place 2013;21:180-91.

28 Wilson DB, Gottfredson DC, Najaka SS. School-Based prevention of problem behaviors: a meta-analysis. J Quant Criminol 2001;17:247-72.

29 Okcu S, Ryherd E, Bayer C. The role of physical environment on student health and education in green schools. Rev Environ Health 2011;26:169-79.

30 Morton KL, Atkin AJ, Corder K, et al. The school environment and adolescent physical activity and sedentary behaviour: a mixedstudies systematic review. Obes Rev 2016;17:142-58.
31 Ferreira I, van der Horst K, Wendel-Vos W, et al. Environmental correlates of physical activity in youth - a review and update. Obes Rev 2007;8:129-54.

32 Venturelli F, Ferrari F, Broccoli S, et al. The effect of public Health/ Pediatric obesity interventions on socioeconomic inequalities in childhood obesity: a scoping review. Obes Rev 2019;20:1720-39.

33 Frerichs L, Brittin J, Sorensen D, et al. Influence of school architecture and design on healthy eating: a review of the evidence. Am J Public Health 2015;105:e46-57.

34 Naylor P-J, Nettlefold L, Race D, et al. Implementation of school based physical activity interventions: a systematic review. Prev Med 2015;72:95-115.

35 Micha R, Karageorgou D, Bakogianni I, et al. Effectiveness of school food environment policies on children's dietary behaviors: A systematic review and meta-analysis. PLoS One 2018;13:e0194555-27

36 Hollis JL, Sutherland R, Williams AJ, et al. A systematic review and meta-analysis of moderate-to-vigorous physical activity levels in secondary school physical education lessons. Int J Behav Nutr Phys Act 2017:14:52.

37 Fletcher A, Bonell C, Hargreaves J. School Effects on Young People's Drug Use: A Systematic Review of Intervention and Observational Studies. Journal of Adolescent Health 2008;42:209-20.

38 Verjans-Janssen SRB, van de Kolk I, Van Kann DHH, et al. Effectiveness of school-based physical activity and nutrition interventions with direct parental involvement on children's BMI and energy balance-related behaviors - A systematic review. PLoS One 2018;13:e0204560-24

39 Baumann N. How to use the medical subject headings (mesh). Int $J$ Clin Pract 2016;70:171-4.

40 Muellmann S, Landgraf-Rauf K, Brand T. Wirksamkeit von schulbasierten Interventionen Zur Prävention und/oder Reduktion psychosozialer Probleme bei Kindern und Jugendlichen: ein review von reviews. Gesundheitswesen 2017;79.

41 Viner RM, Ozer EM, Denny S, et al. Adolescence and the social determinants of health. Lancet 2012;379:1641-52.

42 Raphael D. Adolescence as a gateway to adult health outcomes. Maturitas 2013;75:137-41.

43 Diez-Roux AV. Bringing context back into epidemiology: variables and fallacies in multilevel analysis. Am J Public Health 1998:88:216-22.

44 Diez-Roux AV. Multilevel analysis in public health research. Annu Rev Public Health 2000;21:171-92.

45 Högberg B, Strandh M, Petersen S, et al. Education system stratification and health complaints among school-aged children. Soc Sci Med 2019;220:159-66.

46 Baumert J, Stanat P, Watermann R. Schulstruktur und die Entstehung differenzieller Lern- und Entwicklungsmilieus. In: Baumert J, Stanat P, Watermann R, eds. Herkunftsbedingte Disparitäten Im Bildungswesen: Differenzielle Bildungsprozesse und Probleme Der Verteilungsgerechtigkeit. Wiesbaden: VS Verlag für Sozialwissenschaften, 2006

47 Hoffmann S, Wachtler B, Sander L. Health inequalities among infants and pre-school children: protocol for a scoping review examining the Moderating and mediating role of contextual and compositional family characteristics, 2020

48 Hilger-Kolb J, Schneider S, Herr R, et al. Associations between contextual and compositional characteristics of early childcare facilities with health, health behaviours and well-being among young children aged 06 years: protocol for a scoping review. BMJ Open 2020;10:e037038.

49 Matos Fialho PM, Dragano N, Reuter M, et al. Mapping the evidence regarding school-to-work/university transition and health inequalities among young adults: a scoping review protocol. BMJ Open 2020;10:e039831.

50 Liberati A, Altman DG, Tetzlaff J, et al. The PRISMA statement for reporting systematic reviews and meta-analyses of studies that evaluate healthcare interventions: explanation and elaboration. $B M J$ 2009;339:1-27.

51 Tricco AC, Lillie E, Zarin W, et al. PRISMA extension for scoping reviews (PRISMA-ScR): checklist and explanation. Ann Intern Med 2018;169:467-73.

52 Herke M, Moor I, Winter K, et al. Role of contextual and compositional characteristics of schools for health inequalities in childhood and adolescence: protocol for a scoping review. BMJ Open 2020;10:e038999.

53 Swiss Academic Software GmbH. Citavi 6 (Version 6.5.0.0) [program]. Wädenswil, Switzerland: Swiss Academic Software GmbH, 2020.

54 Centre for Reviews and Dissemination. Systematic Reviews.. CRD's guidance for undertaking reviews in health care. Centre for Reviews and Dissemination, University of York: York, 2009. 
55 Ogilvie D, Fayter D, Petticrew M, et al. The harvest plot: a method for synthesising evidence about the differential effects of interventions. BMC Med Res Methodol 2008;8:1-7.

56 Bartelink $\mathrm{N}$, van Assema $\mathrm{P}$, Jansen $\mathrm{M}$, et al. The Moderating role of the school context on the effects of the healthy primary school of the future. Int J Environ Res Public Health 2019;16. doi:10.3390/ ijerph16132432. [Epub ahead of print: 0907 2019].

57 Bonell C, Beaumont E, Dodd M, et al. Effects of school environments on student risk-behaviours: evidence from a longitudinal study of secondary schools in England. J Epidemiol Community Health 2019;73:502-508.

58 Demment M, Wells N, Olson C. Rural middle school nutrition and physical activity environments and the change in body mass index during adolescence. J Sch Health 2015;85:100-8.

59 Desousa C, Murphy S, Roberts C, et al. School policies and binge drinking behaviours of school-aged children in Wales--a multilevel analysis. Health Educ Res 2008;23:259-71.

60 Dubuisson C, Lioret S, Dufour A, et al. Associations between usual school lunch attendance and eating habits and sedentary behaviour in French children and adolescents. Eur J Clin Nutr 2012;66:1335-41.

61 Fernandes M, Sturm R. Facility provision in elementary schools: correlates with physical education, recess, and obesity. Prev Med 2010;50 Suppl 1:S30-5.

62 Goodman E, Huang B, Wade TJ, et al. A multilevel analysis of the relation of socioeconomic status to adolescent depressive symptoms: does school context matter? J Pediatr 2003;143:451-6.

63 Grüttner M. [Eating Disorders in Female High School Students: Educational and Migration Background, School-Related Stress and Performance-Orientated Classes]. Gesundheitswesen 2018;80:S5-11.

64 Haug E, Torsheim T, Samdal O. Physical environmental characteristics and individual interests as correlates of physical activity in Norwegian secondary schools: the health behaviour in school-aged children study. Int J Behav Nutr Phys Act 2008;5:47.

$65 \operatorname{Hood}$ NE, Colabianchi N, Terry-McElrath YM, et al. Physical activity breaks and facilities in US secondary schools. J Sch Health 2014;84:697-705.

66 Huisman C, Bruggeman J. The social network, socioeconomic background, and school type of adolescent smokers. Int J Behav Dev 2012;36:329-37.

67 Huisman C, van de Werfhorst HG, Monshouwer K. Adolescent tobacco use in the Netherlands: social background, education, and school organization. Youth \& Society 2012;44:567-86.

68 Kuipers MAG, de Korte R, Soto VE, et al. School smoking policies and educational inequalities in smoking behaviour of adolescents aged 14-17 years in Europe. J Epidemiol Community Health 2016;70:132-9.

69 Lewis L, Maher C, Katzmarzyk P, et al. Individual and SchoolLevel socioeconomic gradients in physical activity in Australian schoolchildren. J Sch Health 2016;86:105-12.

70 Li J, Hooker NH. Childhood obesity and schools: evidence from the National survey of children's health. J Sch Health 2010;80:96-103.

71 Martin MA, Frisco ML, Nau C, et al. Social stratification and adolescent overweight in the United States: how income and educational resources matter across families and schools. Soc Sci Med 2012;74:597-606.

72 Moore GF, Littlecott HJ, Evans R, et al. School composition, school culture and socioeconomic inequalities in young people's health: multi-level analysis of the health behaviour in school-aged children (HBSC) survey in Wales. Br Educ Res J 2017;43:310-29.

73 O'Hara JK, Haynes-Maslow L. Examining the association between school Vending machines and children's body mass index by socioeconomic status. J Nutr Educ Behav 2015;47:526-31.

74 Olsson G, Fritzell J. A multilevel study on ethnic and socioeconomic school stratification and health-related behaviors among students in Stockholm. J Sch Health 2015;85:871-9.

75 Piccolo LR, Merz EC, Noble KG, et al. School climate is associated with cortical thickness and executive function in children and adolescents. Dev Sci 2019;22:e12719.

76 Shackleton N, Allen E, Bevilacqua L, et al. Associations between socio-economic status (including school- and pupil-level interactions) and student perceptions of school environment and health in English secondary schools. Br Educ Res J 2018;44:748-62.

77 Van Hook J, Altman CE. Competitive food sales in schools and childhood obesity: a longitudinal study. Sociol Educ 2012;85:23-39.

78 Virtanen M, Kivimäki H, Ervasti J, et al. Fast-Food outlets and grocery stores near school and adolescents' eating habits and overweight in Finland. Eur J Public Health 2015;25:650-5.

79 Virtanen M, Kivimäki M, Luopa P, et al. Staff reports of psychosocial climate at school and adolescents' health, truancy and health education in Finland. Eur J Public Health 2009;19:554-60.

80 Wills W, Backett-Milburn K, Gregory S, et al. The influence of the secondary school setting on the food practices of young teenagers from disadvantaged backgrounds in Scotland. Health Educ Res 2005;20:458-65

81 Youngblade LM, Theokas C, Schulenberg J, et al. Risk and promotive factors in families, schools, and communities: a contextual model of positive youth development in adolescence. Pediatrics 2007;119:S47-53.

82 Akshoomoff N, Newman E, Thompson WK, et al. The NIH Toolbox cognition battery: results from a large normative developmental sample (ping). Neuropsychology 2014;28:1-10.

83 PISA O. Results: what makes schools successful? resources, policies and practices (volume IV). 2013. Pisa: OECD Publishing, 2012.

84 Markham WA, Aveyard P. A new theory of health promoting schools based on human functioning, school organisation and pedagogic practice. Soc Sci Med 2003;56:1209-20.

85 Marsh HW, Trautwein U, Lüdtke O, et al. Social comparison and big-fish-little-pond effects on self-concept and other self-belief constructs: role of generalized and specific others. J Educ Psychol 2008;100:510-24.

86 Burk WJ, Steglich CEG, Snijders TAB. Beyond dyadic interdependence: Actor-oriented models for co-evolving social networks and individual behaviors. Int J Behav Dev 2007;31:397-404.

87 Bronfenbrenner U. The ecology of human development: experiments by nature and design. Cambridge: Harvard University Press, 1979.

88 Eccles JS, Roeser RW. Schools, Academic Motivation, and StageEnvironment Fit. In: Lerner RM, Steinberg L, eds. Handbook of adolescent psychology. 8. Ausgabe: John Wiley \& Sons, 2009.

89 Dijkstra P, Kuyper H, van der Werf G, et al. Social comparison in the classroom: a review. Rev Educ Res 2008;78:828-79.

90 UNESCO. International Standard Classification of Education - ISCED 2011. Montreal: UNESCO Institute for Statistics, 2012.

91 United Nations. World economic situation and prospects 2020. New York: United Nations, 2020. 